\title{
SMART DAM SYSTEM
}

\author{
Vishal Wankhade \\ Department Of Information- \\ Technology \\ Shah \& Anchor Kutchhi \\ Engineering College, \\ Mumbai, Maharashtra India
}

\author{
Aniket Thakker \\ Department Of Information- \\ Technology, \\ Shah \& Anchor Kutchhi Engineering \\ College, \\ Mumbai, Maharashtra India \\ Harish Motekar \\ Department of Information \\ Technology \\ Shah \& Anchor Kutchhi Engineering \\ college \\ Mumbai, Maharashtra India
}

\author{
Dishant Vakte \\ Department Of Information- \\ Technology \\ Shah \& Anchor Kutchi \\ Engineering College, \\ Mumbai, Maharashtra India
}

\begin{abstract}
With increase in global warming and ever changing temperature the rate of water in dam and temperature affects millions of people and damages the economy if any incident were supposed to happen due to human error so with the help of our automated dam system we have very efficiently solved it with the help of temperature sensor and advanced Ultrasonic sensor we have automated the dam gate opening process so that the gate of dam is automatically opened when there are chances of dam being overflowed or damaged. Using ultrasonic sensor and a temperature system to simultaneously support the decision of dam door functionality helped in overcoming accidental and falsetriggered data. Using these two in co-relation makes system less prone to error and increases the efficiency by multiple times.
\end{abstract}

Keywords - Dam System, Ultrasonic sensor, Temperature, Smart Dam System.

\section{INTRODUCTION}

Human error can play a fatal role in opening and closing of dam gate and can do a lot of damage to the people and national economy that rely on the dam for water and other hydro electricity. If dam is not opened at the correct time it can burst or collapse due to increased water pressure, if the dam is not closed on the exact time it can flood the villages along the water path and banks of the river causing severe damage, So automation is required to minimize this error. To further avoid human error we used dual mechanism that is Ultrasonic sensor along with temperature sensor that both provide each other with fail safe mechanism and each sensor keeping other in check, this helps in reducing triggering by false/unexpected triggers and helps in avoiding unwanted mishaps. This dual sensor feature also takes into account the physics of thermo dynamic expansion, it plays a huge role in dams as slight temperature variation can cause rocks to expand, it may not be visible to naked eye but the microscopic pores expand and the water pressure being to high even the slightest change in temperature can have major impact on the threshold of the dam. This law of physics is also taken into consideration and our system is apt in intelligently readjusting the threshold of the dam based on it's surrounding, To further enhance the threshold and to avoid a complete fatal outcome we have added functionality to open gates slightly and not whole this helps a lot in reducing the pressure by slightly opening the dam door even for a few seconds can avoid damage to dam due to increased water pressure and thus reducing the future risk of dam collapse.

\section{REVIEW OF LITERATURE}

Global warming has become a topic of grave concern to the modern society. Global sea levels are now rising by 3.6 millimeters per year, up from an average rate of $1.4 \mathrm{~mm}$ per year last century. In just 80 years, the ocean could be more than 1 meter ( 3.3 feet) taller than it is today. This means that all the settlements living near water, be it the tribal areas or the most modern cities, are in grave danger. The glaciers all over the world have been melting faster than ever before and causing heavy damage to life and property, the latest example being the unfortunate flash floods of Uttarakhand in February 2021. Although fighting global warming is a long battle, flooding of rivers is an issue which needs our utmost attention right now. It needs rapid, accurate and error-free response. This can be achieved by automating damns which not only are free from human error, but also give proper 


\section{International Journal of Engineering Applied Sciences and Technology, 2021 \\ Vol. 5, Issue 12, ISSN No. 2455-2143, Pages 147-150 \\ Published Online April 2021 in IJEAST (http://www.ijeast.com)}

response to localities nearby to evacuate in extreme circumstances.

The rising temperature of earth also plays a huge part in the maintenance of dams. The January 2021 global land and ocean surface temperature was $0.80^{\circ} \mathrm{C}\left(1.44^{\circ} \mathrm{F}\right)$ above the 20 th century average and ranked as the seventh warmest January in the 142-year global records. Since the dams are made out of stones, they are prone to cracking. Such rising temperature cause the water to expand and make these cracks wider, thus posing a great to the integrity of the structure. And if the dam breaks, that could put the nearby settlements to a life threatening risk. A wise move would be to decrease the pressure of the dam during this period, but its is impossible for humans to keep a check on temperature levels manually, hence a smart dam is required to intelligently keep a check on temperature and take actions accordingly.

\section{CIRCUIT AND COMPONENTS}

To automate the process, we have created an intricate circuit to avoid any failure of the system. We have used Ultrasonic sensor as a primary decider whether gate will open or close which is further dependent on the temperature detector that detects the environment as well as water temperature. This process of each sensor depending on other sensor to intelligently make decision based on its surrounding, adds an extra security layer, by doing so we further enhance the efficiency of the system, and its versatility to keep changing according to its surrounding. Designing such intricate circuit and providing software to seamlessly adapt to surroundings is done here.

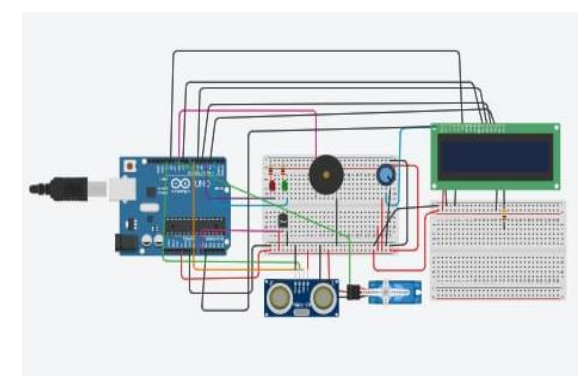

FIg.1 Circuit diagram of the system

\section{A. Ultrasonic sensor:}

Sonar is used by the ultrasonic sensor to calculate the distance to an object. In a simple-to-use kit, it provides excellent noncontact range identification with high sensitivity and reliable readings. From 2 centimeters to 400 centimeters, or 1 inch to 13 feet. Sharp rangefinders are impaired by sunlight and black content, but this one isn't. This excellent accuracy makes ultrasonic sensor the best choice for detection in this smart dam system as accuracy is very important.

Ultrasonic sensor is the primary decider whether the gate of dam will open or close this is done by monitoring the water level Ultrasonic sensor will trigger the door open when it detects water is above the maximum level and opens the door. As soon as water recedes below the maximum point IR sensor closes the gates. IR sensor is very precisely calibrated so it can exactly close and open the gates as set by the scientists.

\section{B. Temperature Sensor:}

A temperature sensor is a device that transforms thermal energy into physical quantities like mechanical energy, pressure, and electrical signals, among other things. The electrical potential difference in a temperature sensor, for example, is caused by a temperature difference around its terminals. As a result, a thermocouple is a temperature sensor. Dam is not only dependent upon water level but also the weather around it dam needs to adjust to various weather conditions and maximum water levels keep on changing due to ever changing temperature. Temperature sensor detects change in temperature and helps ultrasonic sensor to open/close the dam gate accordingly.

\section{Example:-}

i. In winter season due to cold weather the dam walls shrink or contract so the maximum level of water can be raised as the minute cracks in the dam walls are contracted and are tightly closed,

ii. In summer season due to warm weather the dams walls expand so the maximum level of water needs to be reduced as minute cracks formed in the dam wall expand and cannot handle additional water pressure.

\section{Arduino Uno:}

Arduino Uno acts as a micro controller and helps in connecting various sensors, $\mathrm{i} / \mathrm{p}$ and $\mathrm{o} / \mathrm{p}$ lines to communicate with each other. Arduino provides a fast and efficient response times compared to other controllers and hence is beneficial as this dam system is a very precise function, any latency would result in colossal damage. Arduino uno provides good cpu management as well as low latency, this helps in reducing latency due to hardware based conditions. Arduino uno makes it easy for us to convert analog signals to digital signals i.e ADC to DAC. It comes with a power supply and an inbuilt cpu that stores the code which makes it easier and safe as it dosen't require external hardware that stores the code this increases the security feature as the external device can be easily hacked and can cause microcontroller to fail. 


\section{International Journal of Engineering Applied Sciences and Technology, 2021 \\ Vol. 5, Issue 12, ISSN No. 2455-2143, Pages 147-150 \\ Published Online April 2021 in IJEAST (http://www.ijeast.com)}

\section{LCD:}

Millions of pixels make up the images or pictures shown on the LCD TV screen. Each pixel is a distinct red, green, or blue light that is turned on or off to create the image shown on the screen. As electricity is applied to Nematic liquid crystal, it straightens out from its twisted state.

LCD screen is used to show various ongoing operations as well as status of the dam gate and temperature to the concerned authority.

\section{E. Piezo Sensor:}

Piezoelectric transducers are electroacoustic transducers that convert pressure or mechanical stress into an alternating electrical power. It's used to calculate physical quantities that aren't strictly measurable, such as force, strain, tension, and so on.

When gates are closing/opening a sound alarm is placed so it can warn authority that the process is undergoing a change and to take shelter as dam gates are being closed/opened.

\section{CONNECTIONS AND WORKING}

The ultrasonic sensor's trigger is connected to the pin D7 and echo to pin D9 of the Arduino board. The piezoelectric is connected to the pin D10. The microservo is connected to the pin D11. The LCD is connected to A1, 12,9,6,5 and 3 pin. The temperature sensor is connected to the A0 pin.

Upon simulation, the ultrasonic sensor measures the water level in the dam in $\mathrm{cm}$. and the temperature sensor measures the temperature of the water in the dam. There are 4 circumstances that can occur:

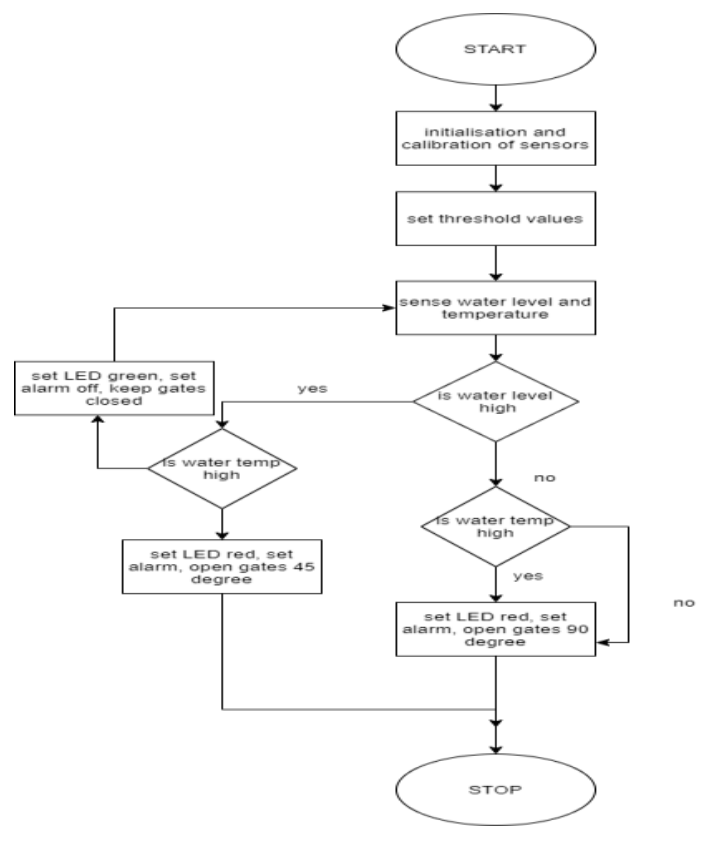

Fig.2 Flowchart of the System

1. Normal water level and temperature The green LED is lit and the doors (micro servo) is closed. Lcd displays normal temp and message

2. High water level and normal temperature The red LED is lit, the piezo is triggered and the door opens. Lcd displays alert.

3. Normal water level and low temperature The red LED is lit, the piezo is triggered and the door opens partially.

4. High water level and low temperature. The red LED is lit, the piezo is triggered and the door opens partially.

\section{CONCLUSION}

This dam system helps increase the accuracy of the dam gates opening and closing system which in turn helps the economy and saves lives. It also reduces the chances of human error as it can also be placed as a security check system that checks whether all the conditions are met to open/ close the dam gate which adds an extra and essential layer of security. And helps achieve greater, higher, accurate and reliable results.

\section{REFERENCES}

[1] Rapelli Navin, Myakal Ashish, Kota Vyankatesh, Rajarapollu Prachi R. (2019). "IOT Based Smart Water 
Management Monitoring and Distribution System for an Apartment", Intelligent Computing and Control Systems (ICCS) 2019 International Conference on, pp. 440-443, 2019.

[2] S.M. Saifur Rahman Faisal, Iftekhar Uddin Ahmed, Humayun Rashid, Remon Das, Md. Mobarak Karim, S M Taslim Reza. (2017). "Design and Development of an Autonomous Floodgate using Arduino Uno and Motor Driver Controller" Proceedings of the 2017 4th International Conference on Advances in Electrical Engineering pp 28-30 September, 2017, Dhaka, Bangladesh.

[3] Siddula Sai Sreekar, Jain P.C., Upadhayay Madhur Deo. "Real Time Monitoring and Controlling of Water Level in Dams using IoT" 201*IEEE 8th International Advance Computing Conference (IACC). pp.87-91

[4] Puig V, Ocampo-Martinez C, Romera J, Quevedo J, Negenborn R, Rodriguez P and de Campos S. (2012). "Model predictive control of combined irrigation and water supply systems: Application to the Guadiana river", Proceedings of 2012 9th IEEE International Conference on Networking, Sensing and Control, pp. 85 - 90, 2012.

[5] Litrico X. (2002). "Robust IMC flow control of SIMO dam-river open-channel systems", IEEE Transactions on Control Systems Technology, vol. 10,no. 3, pp. 432-437, 2002

[6] Guo J and Chen Q. (2010). "An Application of Fuzzy Control Based on PLC in Rubber Dam Monitoring System", 2010 International Conference on System Science, Engineering Design and Manufacturing Informatization, vol. 2, pp. $266-269,2010$

[7] Inyiama H. C. and Obota M. E., "Designing Flood Control Systems Using Wireless Sensor Networks", Intern pp. $12-15$

[8] Nandaniya M. (2013). "A Review Paper of Automatic Canal Gate Control of Induction Motor with PLC and VFD, Powered by Solar System and Monitoring by SCADA", International Journal of Emerging Trends in Electrical and Electronics (IJETEE), vol. 1, no. 1, pp. 32-39, 2013.

[9] Iyer M, Pai S, Badri S and Kharche S. (2013). "Embedded Dam Gate Control System using ' $C$ ' and Visual Basic", International Journal of Computer Applications (0975 - 8887), vol. 69, no. 2, pp. 32-37, 2013.

[10] S. Md. Umar Talha, Mohani S. Sheraz, S. Hassan Ahmed and M. Ebrahim, (2012) "Design for an Irrigation and Monitoring System of an Automated Dam", Proceedings of the International MultiConference of Engineers and Computer Scientists, vol. 2, pp. 65-67, 2012.

[11] Sathya V, Arun Kshitij, Mahajan Harshitaa, Kumar Singh Amit. (2019) "Automate the Functioning of Dams Using IoT" 2019 3rd International Conference on Computing Methodologies and Communication (ICCMC) pp. 71-75

[12] Dr. Shivappa Nagesha, Rao Aishwarya S, T Aishwarya, Athreya Jahnavi S, H Mandakini. (2020). Dam
Automation using IoT, INTERNATIONAL JOURNAL OF ENGINEERING RESEARCH \& TECHNOLOGY (IJERT) Volume 09, Issue 05 pp. 68-71 (May 2020) 